\title{
Zoster vaccine live for the prevention of shingles in the elderly patient
}

\author{
Jamie Zussman \\ Lorraine Young \\ Department of Medicine, \\ Dermatology Division, David Geffen \\ School of Medicine at the University \\ of California, Los Angeles, California
}

Correspondence: Lorraine Young UCLA Med-Derm, BOX 956957, 200 Med Plaza \#450, Los Angeles, CA 90095-6957, USA

Tel + I 3109173376

$\mathrm{Fax}+\mathrm{I} 3102069878$

Email lcyoung@mednet.ucla.edu

\begin{abstract}
Shingles, also known as herpes zoster, is a common disease in the elderly population that is caused by reactivation of latent varicella zoster virus. Its manifestations and complications can lead to significant short- and long-term morbidity. In 2006, the United States Food and Drug Administration approved Zoster Vaccine Live (Zostavax ${ }^{\circledR}$ ) for the prevention of herpes zoster in immunocompetent adults age 60 and over. The approval was based on the results of a large, multi-center clinical trial, the Shingles Prevention Study. This study showed that vaccination significantly decreased shingles incidence, burden of illness due to disease, and the development of, and severity of postherpetic neuralgia. This review offers an overview of varicella zoster virus infection and complications, a summary of the Shingles Prevention Study, and a critical analysis designed to aid the practicing physician who has questions about vaccine administration.
\end{abstract}

Keywords: zoster vaccine, shingles, herpes zoster, postherpetic neuralgia, zostavax

\section{Introduction}

Herpes zoster (HZ) is a highly prevalent disease in the United States with approximately one million cases diagnosed annually (Insinga et al 2005; Oxman et al 2005). The majority of those affected are older individuals; susceptibility to the disease begins to increase at age 50 and by age 60 adults are 8 to 10 times more likely to develop $\mathrm{HZ}$ and significantly more prone to develop complications than their younger counterparts (Gilden et al 2000; Kimberlin and Whitley 2007). About 30\% of people will experience at least one episode during their lifetime and this lifetime risk increases to $50 \%$ if one lives to age 85 (Brisson et al 2001; Dworkin et al 2007). In the Duke Established Populations for Epidemiological Studies of the Elderly, a multi-center population survey of adults aged 65 and older, the risk of developing $\mathrm{HZ}$ increased by an odds ratio of 1.2 for every five-year increase in age after age 65 (Schmader et al 1995). In 2005, the US Census Bureau reported that 49 million people in the United States were 60 years of age or older, a number expected to double by 2030 (USCB 2004). The World Health Organization defines an elderly person as one who is 65 years of age or older; and as this population in the United States quickly expands, it is probable that $\mathrm{HZ}$ will become only more common (WHO 2007).

On May 25th, 2006, the United States Food and Drug Administration (FDA) approved Zoster Vaccine Live, a live-attenuated vaccine for varicella-zoster virus (VZV). This signaled recognition by health officials of the need to prevent and combat this disease more effectively. Although licensing of the vaccine was a major step, many uncertainties remain regarding the vaccine's long-term effects, efficacy, and cost-effectiveness. This review will address these questions, but will first review the pathophysiology and lasting sequelae of $\mathrm{HZ}$, summarize the relevant data and clinical trials involving Zoster Vaccine Live, and offer practical recommendations for vaccine administration in the elderly patient. 


\section{Varicella-zoster virus infection Primary infection}

VZV, also known as human herpes virus 3, has a genome composed of a single, linear, double-stranded DNA. Upon initial infection, the common childhood exanthem known as both chicken pox and varicella, is manifested. The dermatological signs typically follow a short catarrhal phase and consist of numerous vesicles on erythematous bases. These are distributed over the entire body in various stages of crust formation and healing. It is normally a self-limited, benign disease with only rare long-term consequences. In the United States, $95.5 \%$ of people aged $20-29,98.9 \%$ of people aged $30-39$, and more than $99.6 \%$ of people over age forty show seropositivity to the virus (Kilgore et al 2003).

\section{Reactivation}

Most commonly, after resolution of the primary infection, VZV remains dormant in sensory nerve root ganglia (Opstelten et al 2002). However, reactivation of VZV, known as shingles, or HZ, may always occur, and may be precipitated by any condition that weakens the immune system. Common conditions that increase susceptibility to HZ are HIV and AIDS, chronic immunosuppressive therapy, radiotherapy, intensely stressful life events, and the normal deterioration of cell-mediated immunity associated with aging (Gnann and Whitley 2002; Levin et al 2003). An epidemiologic study of 786 men clearly demonstrated the strong effect of immunosuppression on disease incidence by finding that HIV seropositivity conferred a relative risk of 16.9 for the development of HZ compared with healthy controls (Buchbinder et al 1992). Immunosuppression from any cause is believed to increase disease frequency by 20 to 100 times (Schmader 2007a).

Hope-Simpson (1965) proposed that one possible explanation for the relatively lesser incidence of $\mathrm{HZ}$ in immunocompetent persons is that subclinical reactivations of small amounts of latent virus may occur, acting as "boosters" to stimulate the immune system. A similar justification has been proposed to explain why secondary episodes of reactivation in immunocompetent persons occur only rarely. The first episode of $\mathrm{HZ}$ serves to activate the immune system, increasing varicella antibody titers and varicella-specific cellular immunity (Taha et al 2006; Kimberlin and Whitley 2007). A recently published Italian epidiomiologic study of 26,394 patients aged 14 and over found that over the course of one year, 46 cases of $\mathrm{HZ}$ were diagnosed (1.74 cases $/ 1000$ population per year; $95 \% \mathrm{CI}: 1.28-2.32)$; only three (6.5\%) of the episodes were recurrences and two of the recurrences were in immunocompromised patients (Legami et al 2007). This increased likelihood of recurrence in patients with impaired immunity was also illustrated in a study of 1044 patients with AIDS, which found that of the 163 with a prior history of HZ, 22 (13\%) had a recurrence during the two-year follow-up (Glesby et al 1993).

Clinically, HZ consists of three distinct stages. The prodromal phase lasts for two to three weeks and patients experience neuritic pain, parasthesias, or pruritus, generally localized to one dermatome. This pain is often mistakenly ascribed to the musculoskeletal system as dermatologic manifestations have yet to appear. After the prodrome, acute vesiculation occurs over a period of three to five days and then subsides with the formation of crusts; this may take up to three weeks to occur (Gnann and Whitley 2002). Although VZV is most transmissible during episodes of varicella, the vesicular lesions of $\mathrm{HZ}$ contain high concentrations of virus that may cause primary infection in previously unexposed individuals (Cohen et al 1999). The vesiculation is most often limited to the dermatome that has the highest density of VZV although vesiculation may overlap into adjacent dermatomes in up to 20 percent of cases (Gnann and Whitley 2002). The dermatomes supplied by the trigeminal and thoracic nerves are the most frequent sites of reactivation (Cohen et al 1999). The pain associated with the vesicular stage is clinically significant, a recent study of 160 adults age 60 and older demonstrated that $73 \%$ of subjects still complained of moderate to severe pain seven days after initial presentation. $66.7 \%$ of subjects reported that the pain interfered with their enjoyment of life, $58.3 \%$ said that it interrupted their daily activities, and $\sim 20 \%$ had difficulties with activities of daily living (Schmader et al 2007b). The third clinical stage, if it occurs, is the development of post-herpetic neuralgia (PHN). PHN has multiple definitions, but is commonly defined as neuritic pain that persists in the area of the affected dermatome after the rash has healed, or pain that lasts at least 30 days from the onset of lesions (Young 2006).

\section{Post-herpetic neuralgia}

Although PHN does not occur in every case of HZ, it is still the leading cause of long-lasting morbidity after resolution of the acute outbreak. Its likelihood of developing increases with the age of the patient. In one report, at least $40 \%$ of patients over age 60 , and $75 \%$ over age 70 developed PHN following an episode of HZ (Vander Straten et al 2001). In comparison, multiple studies have suggested that children and adolescents have either no risk, or an extremely low risk of developing the condition (Petursson et al 1998; 
Opstelten et al 2002). PHN can last from weeks to years, and is frequently extremely debilitating. This fact is highlighted by a recent study using the Short-form McGill Pain Questionnaire in which patients rated the chronic pain associated with PHN to be more severe than pain associated with rheumatoid arthritis or chronic cancer (Katz and Melzack 1999).

Although there have been many trials testing the efficacy of treatments for PHN, ranging from antiviral therapy (Wood et al 19941; Kost and Straus 1996), to steroids (Eaglestein et al 1970; Keczkes and Basheer 1980; Esmann et al 1987), to dopamine agonists (Galbraith 1983), to antiepileptic agents (Rowbotham 1998; Rice and Maton 2001; Tassone et al 2007), no treatment has adequately shown a reduction in incidence and the pain relief achieved is not close to satisfactory. There have been no controlled trials in which complete pain relief has been achieved. Currently, gabapentin, pregabalin, and the topical lidocaine patch are FDA-approved for the treatment of PHN (Schmader 2007a). These therapies, along with nortriptyline, opiods, and tramadol, are generally used as first-line treatments and some degree of pain relief may be expected in $30 \%-60 \%$ of treated patients (Schmader 2007a). A more detailed analysis comparing the therapeutic effectiveness of agents used to treat PHN may be found in multiple recently published reviews (Young 2006; Saarto and Wiffen 2007; Schmader 2007a).

$\mathrm{PHN}$ is an especially troubling complication in the elderly population where pain medications offer their own set of risks and adverse effects. Pain control is more difficult to achieve in elderly individuals and they are also more likely to experience the adverse effects of new medications due to age related changes in pharmacokinetics and pharmacodynamics. In addition, the elderly are more likely to require hospitalization due to these adverse effects than their younger counterparts (Caranasos et al 1974).

\section{Complications of VZV infection}

In addition to PHN, infection with VZV may lead to other serious, but rare, complications. These include bacterial superinfection, viral dissemination, myelitis, encephalitis, and peripheral and cranial nerve palsies (Galil et al 1997; Hausler et al 2002; Im et al 2007; Kawajiri et al 2007). Reactivation in the ophthalmic region of the trigeminal nerve may lead to blindness, and infection of the geniculate ganglion to facial weakness and occasional hearing disorders (Adour 1994; Garweg and Bohnke 1997). The majority of these complications have very limited treatment options. With our current technologies, it is clear that the most effective way to combat them is by preventing both initial infection and reactivation of $\mathrm{VZV}$.

\section{The VZV vaccine \\ Varivax}

The first VZV vaccine, Varivax ${ }^{\circledR}$, was approved by the FDA in 1995 as a method for preventing primary infection with VZV. Routine vaccination programs with Varivax have been implemented since that time. Varivax is made of the same strain of live-attenuated VZV as found in Zoster Vaccine Live, but contains a much lower dose of virus (Table 1). The dose of the vaccine is determined by the number of plaque-forming units (PFU) of virus that it contains; the monovalent formulation of Varivax contains 1,350 PFU and the quadrivalent formulation, in which Varivax is combined with vaccinations for measles, mumps, and rubella, contains 9,772 PFU. The Oka strain of VZV, used in both vaccines, was acquired from the vesicles of a three-year old Japanese boy infected with VZV and attenuated through multiple laboratory procedures. The vaccine was initially given as one dose to children aged 12-18 months or to any other individual deemed at risk, but follow-up studies have suggested that in vaccinated individuals, immunity to VZV may wane over time (Chaves et al 2007b). For this reason, the Center for Disease Control (CDC) recently modified its schedule to recommend two doses of the vaccine and to include any healthy adult lacking evidence of immunity within its recommendations (Marin et al 2007). Since the vaccination program was begun, the United States has experienced a substantial reduction in morbidity, mortality, and health care costs associated with chicken pox (Davis et al 2004; Nguyen et al 2005). Despite these successes with chicken pox, a reduction in $\mathrm{HZ}$ disease burden has yet to be seen. Because the majority of older individuals living today have already been exposed to VZV, and thus are carriers of latent virus, they remain susceptible to the development of HZ.

\section{$A$ vaccine for patients seropositive for VZV}

Although it is unclear what specifically occurs to allow a reactivation of $\mathrm{VZV}$, general belief is that a gradual reduction in cell-mediated immunity against VZV occurs over time after primary infection. When immunity reaches a critically low level, reactivation may occur. It has been postulated that individuals exposed to active cases of VZV in others may experience a boost in their own immunity against VZV that 
Table I Comparison of Zoster Vaccine Live (Oxman et al 2005; Merck 2007) and Varivax ${ }^{\circledR}$ (Marin et al 2007)

\begin{tabular}{|c|c|c|}
\hline & Zoster Vaccine Live & Varivax ${ }^{\circledR}$ \\
\hline Year of licensure & 2006 & 1995 \\
\hline Vaccine dose & At least $19,400 \mathrm{PFU}$ & I,350 PFU \\
\hline Vaccine strain & Live-attenuated Oka/MerckVZV & Live-attenuated Oka/MerckVZV \\
\hline Immunization population & $\begin{array}{l}\text { Immunocompetent individuals age } \\
60 \text { and older }\end{array}$ & $\begin{array}{l}\text { Vaccination schedule: Ist dose in children } 12-15 \text { months old; } \\
2 \text { nd booster dose at age } 4-6 \text {. Booster dose should be given } \\
\text { to anyone that has only received one dose regardless of age. } \\
\text { Seronegative individuals age } 13 \text { and older should receive } \\
\text { immunization. }\end{array}$ \\
\hline \multirow[t]{4}{*}{ Effectiveness of vaccination } & Vaccination provides: & $70 \%-90 \%$ effective in disease prevention \\
\hline & $\begin{array}{l}\text { Decrease in burden of illness by } \\
61.1 \%\end{array}$ & \\
\hline & $\begin{array}{l}\text { Decrease in incidence of posther- } \\
\text { petic neuralgia by } 66.5 \%\end{array}$ & \\
\hline & $\begin{array}{l}\text { Decrease in incidence of herpes } \\
\text { zoster by } 51 \%\end{array}$ & \\
\hline Incidence of serious adverse Events & $\begin{array}{l}1.4 \% \text { in the Shingles Prevention } \\
\text { Study }\end{array}$ & $0.0026 \%$ in post-marketing surveillance \\
\hline Known duration of protection & $\begin{array}{l}\text { At least four years, long-term } \\
\text { duration unknown }\end{array}$ & $\begin{array}{l}\text { One dose: } 7-10 \text { years Two doses: Increases effectiveness of } \\
\text { disease protection to } 98.3 \% \text { at } 10 \text { years }\end{array}$ \\
\hline
\end{tabular}

Abbreviations: PFU, plaque-forming units; VZV, varicella-zoster virus.

will help to suppress reactivation of the virus (Hope-Simpson 1965). With this concept in mind, preliminary trials examining the use of Varivax in patients already seropositive for VZV were undertaken. Initial data suggested that the number of PFU required to elicit a significant increase in cell-mediated immunity against VZV would have to be at least 14 times greater than the PFU found in the monovalent formulation of Varivax (Levin 2001). The efficacy of a more potent vaccine in preventing $\mathrm{HZ}$ in VZV seropositive subjects was examined in the nationwide Shingles Prevention Study (SPS).

\section{The shingles prevention study Study design}

The SPS was a randomized, double-blind, placebo-controlled study, conducted by the Department of Veterans Affairs, designed to test the effectiveness of the live-attenuated Oka/Merck VZV vaccine for preventing HZ in adults aged 60 and older. The primary endpoint of the study was reduction in burden of illness, defined as a severity-by-duration measure of the total pain and discomfort associated with HZ. The secondary endpoint was the incidence of PHN and other endpoints included incidence of HZ, and the severity of illness. 38,546 subjects were enrolled at 22 different sites and were randomly assigned to receive vaccine or placebo (Oxman et al 2005). To be eligible for participation, subjects must have had a history of primary VZV infection or have resided in the continental United States for over 30 years. Immunocompromised patients, those with a history of prior $\mathrm{HZ}$, and those unable to adhere to study protocol were excluded from the study.

At the onset of the study participants were educated about the signs and symptoms of $\mathrm{HZ}$ and were counseled to contact their study site immediately if they developed a new rash or unilateral pain. Subjects were given a subcutaneous injection of either $0.5 \mathrm{ml}$ of the zoster vaccine or placebo. 12 different vaccine lots were used, varying in potency from 18,700 PFU ( $\sim 14$ times the potency of Varivax) to 60,000 PFU per dose. The median potency was $24,600 \mathrm{PFU}$ with more than $90 \%$ of those vaccinated receiving 32,300 PFU or less (Oxman et al 2005).

Throughout the length of the study, subjects called in to an automated telephone-response system at specified time intervals and were asked a series of standardized questions designed to identify possible cases of HZ. If a suspected case was identified by certain answers, they were instructed to contact their local study site immediately. In clinically suspected cases of HZ, a confirmation of diagnosis was made by viral culture and polymerase-chain reaction assay performed by one central laboratory. If testing was inconclusive, a team of five physicians, blinded to the subject's vaccination status and with an expertise in $\mathrm{HZ}$, made the final determination of disease status (Oxman et al 2005). 
All subjects with a diagnosis of $\mathrm{HZ}$ were required to complete the Zoster Brief Pain Inventory, a questionnaire designed specifically to measure the pain and discomfort associated with HZ. This questionnaire and others were used to examine the effects of $\mathrm{HZ}$ infection on daily living, quality of life, and general health status. During result analysis subjects were stratified by age into one group aged 60-69 and another aged 70 and older. All adverse events occurring within 42 days of vaccination were recorded and all serious adverse events reported by the subject and deemed by the physician to be related to vaccination were recorded throughout the length of the study (Oxman et al 2005).

\section{Results}

Subjects were followed for a mean duration of 3.13 years (range, 1 day to 4.90 years) and $95 \%$ of participants completed the trial. Subjects who withdrew or developed cases of $\mathrm{HZ}$ within the first thirty days following vaccination were excluded from the study results. During the study a total of 960 cases of HZ were confirmed, three were excluded from data analysis because they were the second episode for a subject within the trial period. Of the remaining cases, 642 occurred in the placebo group and 315 in the vaccinated group. Vaccination was shown to significantly reduce the burden of illness $(\mathrm{P}<0.001)$ with a relative reduction in burden of illness in vaccination group compared with placebo of $61.1 \%$ (95\% confidence interval [CI], 51.1 to 69.1 ) (Table 2). The rate of use of antiviral medication (87.3\% in the vaccine group and $85.7 \%$ in the placebo group) and the percentage of subjects who received it within 72 hours (64.1\% in the vaccine group and $65.9 \%$ in the placebo group) were similar between the two groups.

Of the 107 cases of post-herpetic neuralgia that developed, 27 were in the vaccine group and 80 were in the placebo group ( 0.46 case vs. 1.38 cases per 1000 person-years, respectively; $\mathrm{P}<0.001$ ) with vaccination giving a relative reduction of $66.5 \%$ (95\% CI, 47.5 to 79.2 ) (Table 2). The incidence of PHN was more significantly reduced in the 70 and older age group than in the 60-69 age group (Oxman et al 2005). The overall incidence of HZ was significantly reduced from 11.12 per 1000 person years to 5.42 per 1000 person years $(\mathrm{P}<0.001)$, a relative reduction of $51.3 \%(95 \%$ CI, 44.2 to 57.6) (Table 2). Further analysis showed that the vaccine was much more effective at preventing $\mathrm{HZ}$ in 60-69 year olds than it was in those 70 and older. The mean HZ severity of illness score in the vaccine group was significantly lower than in the placebo group (141.2 vs. $180.5, \mathrm{P}=0.008$ ) and the mean duration of pain was also significantly less ( 21 days versus 24 days, $P=0.03$ ). Medications to treat pain associated with $\mathrm{HZ}$ were used with equal frequency among the two groups. The authors reported that the placebo group on average used a greater amount of opiods for a longer period of time, though data and statistics were not presented (Oxman et al 2005).

\section{Adverse events}

The overall incidence of serious adverse events was not statistically different between the vaccine and placebo groups in the SPS as a whole (255 subjects, $1.4 \%$ and 254 subjects, $1.4 \%$ respectively). Study coordinators determined that out of all serious adverse events, two in the vaccine group and three in the placebo group were possibly vaccine-related. Two days after receiving the vaccine a 64-year-old had an asthma exacerbation and after three days an 80-year-old developed symptoms of polymylagia rheumatica. Of those who received placebo, one 65-year-old had an anaphylactic reaction 90 minutes later, a 69-year-old was diagnosed with polymalgia rheumatica after 15 days, and a 78 -year-old was diagnosed with Goodpasture's syndrome on day 52 post injection (Oxman et al 2005).

6616 subjects were enrolled in an adverse events monitoring substudy; these subjects were followed more closely for adverse events with the use of report cards and active monthly surveillance. In this sub-study, the risk of a serious adverse event within 42 days of vaccination was $1.3 \%$ in the placebo group compared with $1.9 \%$ in the vaccine

Table 2 Shingles Prevention Study summary (Oxman et al 2005)

\begin{tabular}{llll}
\hline & Vaccine group & Placebo group & $\begin{array}{l}\text { Relative reduction in vaccine } \\
\text { group compared with placebo } \\
\mathbf{( 9 5 \% ~ c o n f i d e n c e ~ i n t e r v a l , ~} \mathbf{P}<\mathbf{0 . 0 0 1})\end{array}$ \\
\hline Incidence of herpes zoster & & & $51.3 \%(44.2-57.6)$ \\
Incidence of postherpetic neuralgia & 27 cases $/ 19,254$ subjects & 80 cases/19,247 subjects & $66.5 \%(47.5-79.2)$ \\
Burden of illness due to herpes zoster* & 2.21 & 5.68 & $61.1 \%(51.1-69.1)$ \\
\hline
\end{tabular}

Notes: *Burden of illness is a severity by duration measure of the total pain and discomfort experienced during an episode of herpes zoster.A numerical representation is calculated based upon a study subject's answers to the Zoster Brief Pain Inventory. 
group, an increased relative risk of 1.53 (95\% CI, 1.04 to $2.25)$. Those in the vaccine group were also $31.7 \%$ more likely to experience a vaccination site reaction than those in the placebo group. Many vaccinated subjects experienced erythema (1188 subjects, $35.8 \%$ ), pain or tenderness (1147 subjects, $34.5 \%$ ), swelling (871 subjects, $26.2 \%$ ), and pruritus (237 subjects, $7.1 \%$ ) at the injection site. There was a $0.1 \%$ incidence of varicella-like rashes at the injection site of vaccine recipients compared with $0.04 \%$ of placebo recipients $(\mathrm{P}<0.05)($ Oxman et al 2005).

\section{Clinical use}

The SPS offered extremely promising results and after FDA-approval, the $\mathrm{CDC}$ issued its recommendation that individuals 60 and older be vaccinated. The Advisory Committee on Immunization Practices (ACIP) expanded upon the recommendations of the $\mathrm{CDC}$ to clarify that vaccination should be provided to eligible individuals even if they do not have a history of primary clinical infection, if they were born United States before 1980 (and may therefore be considered seropositive for VZV) (Marin et al 2007). In addition, even though the SPS did not include subjects with histories of prior HZ, the ACIP also recommended that these individuals be included in any $\mathrm{HZ}$ vaccination program (Marin et al 2007). Preliminary analysis has shown that based on a cost of US\$150 per vaccine dose, estimated cost per qualityadjusted life for Zoster Vaccine Live is comparable with that of the pneumococcal vaccine, already in widespread use among the elderly population (Messonnier and Zhou 2006). 18 people would need to be vaccinated in order to prevent one case of $\mathrm{HZ}$ and 109 people would need to be vaccinated to prevent one clinically significant case of PHN (Oxman 2007).

Physicians planning to administer the vaccine must have the capability to store the vaccine at -15 degrees Celsius ( +5 degrees F). The distributed vaccine has been formulated to contain a minimum of 19,400 PFU in a $0.65 \mathrm{ml}$ dose (a $0.5 \mathrm{ml}$ formulation was used in the SPS). It should be administered by subcutaneous injection no longer than thirty minutes after reconstitution with provided diluent and discarded if not used within this time. Physicians should also be aware that the vaccine is not approved for use in anyone with innate or acquired immunodeficiency because it is a live vaccine. The vaccine is contraindicated in pregnant women, people with untreated, active tuberculosis, those with a history of anaphylactic reactions to gelatin, neomycin, or any other vaccine component, and people with any type of immunodeficiency or those on immunosuppressive therapy (Table 3). The ACIP recommends that persons chronically taking more than $2 \mathrm{mg} / \mathrm{kg}$ per day of corticosteroids or those on $20 \mathrm{mg} /$ day of prednisone for two weeks or more should be considered immunosuppressed and should not receive the live vaccine (Kroger et al 2006).

Transmission of the vaccine virus was not reported in the SPS, and vaccine virus was not isolated from any immunized study participants who developed rashes, including those with a varicella-like presentation (Oxman et al 2005). However, the vaccine labeling warns that transmission of the vaccine virus may occur between

Table 3 Prescription recommendations for Zoster Vaccine Live

Is Zoster Vaccine Live appropriate for my patient?
I) Is my patient 60 years of age or older?
Zoster Vaccine Live is only FDA-approved for use in patients 60 and above.
2) Does my patient have any characteristic for which administration of a live vaccine could be unsafe?
Any condition or situation that compromises a patient's immune system is a contraindication to vaccine administration. This includes:
- Chronic immunosuppressive therapy such as chemotherapy or high-dose corticosteroids.
- Any primary or acquired immunodeficiency state, including AIDS.
- Active, untreated tuberculosis.

3) Does my patient have a history of anaphylactic reaction to any vaccine component?

Zoster Vaccine Live contains gelatin and neomycin, along with many other ingredients. A history of neomycin-induced contact dermatitis is not a contraindication to vaccination.

4) Is my patient pregnant?

Patients should wait four weeks after vaccination to conceive and should not be vaccinated while pregnant.

5) My patient is currently suffering from postherpetic neuralgia. Will vaccination relieve his/her symptoms? Zoster Vaccine Live is indicated for the prevention of herpes zoster and its complications. It is not a treatment for active cases of herpes zoster or postherpetic neuralgia. 
vaccinees who develop a varicella-like rash and susceptible contacts (Merck 2007). Eight separate cases of possible transmission have been reported during postlicensure safety surveillance though no serious clinical consequences have been noted (Chaves 2007a). Physicians should warn patients, even those who do not develop a varicella-like rash, of the small but definite risk of transmitting the virus to varicella-susceptible individuals, especially those who may develop serious adverse effects from contraction of the virus such as pregnant women and unvaccinated infants.

\section{Discussion}

The SPS provides solid evidence that vaccination with Zoster Vaccine Live significantly reduces the burden of illness of $\mathrm{HZ}$, the incidence and severity of PHN, and the incidence of $\mathrm{HZ}$ in people age 60 and older. This news comes at an especially critical time as our elderly population, and hence the number of people at risk for the development of $\mathrm{HZ}$, is quickly expanding. According to the results of the SPS, if a routine immunization program were properly implemented, up to 250,000 cases of HZ may be prevented every year (Burke 2007). There have been multiple published costeffectiveness analyses since the reporting of the SPS results. One, which was carried out using data from the SPS, and a commonly accepted cost-effectiveness threshold of $\$ 50,000$ per quality-adjusted life year gained, was presented at the ACIP's 2006 meeting; it demonstrated that vaccination is cost-effective for immunocompetent adults age 60 and older (Pellisier 2006). Another initial analysis using similar criteria suggested that the annual economic cost of a vaccination program may exceed the cost of annual HZ infections (Hornberger and Robertus 2006). An additional article demonstrated that cost-effectiveness varies significantly with sex and with age at time of vaccination (Rothberg et al 2007). This study suggests that cost-effectiveness may range from an acceptable US $\$ 44,000$ per quality-adjusted life year saved for a 70-year-old woman to US\$191,000 per quality-adjusted life year saved for an 80-year-old man (Rothberg et al 2007). However, until more time has passed, and information on length of vaccine efficacy is documented, this issue cannot be definitively resolved. Furthermore, along with budgetary implications, the societal benefits offered by any vaccination program must also be considered. With successful vaccination against $\mathrm{HZ}$, there will be decreased risk of transmission of VZV to seronegative persons, increased productivity in the work force as burden of illness and incidence are both significantly reduced, and with each case of $\mathrm{HZ}$ resulting in an average of two outpatient doctor's visits, reduced strain on an already overwhelmed healthcare system (Hornberger and Robertus 2006).

Vaccination against $\mathrm{HZ}$ is also particularly relevant today as a routine immunization program with Varivax, to prevent primary VZV infection, has been implemented. The number of primary VZV infections has been reduced by $70 \%-90 \%$ and concern has been raised that $\mathrm{HZ}$ incidence will rise in elderly persons who will no longer experience frequent exposures to VZV (Chaves et al 2007c; Marin et al 2007). This concept was recently investigated in a countrywide population survey of 3,675 individuals aged 65 and older that attempted to objectively determine whether exposure to primary VZV infection reduced the risk of HZ (Chaves et al 2007c). The survey found no statistical difference in $\mathrm{HZ}$ incidence in those that had been exposed to chickenpox in the past decade and those who had not. However, the study was flawed in that it depended on the self-reporting by elderly individuals in regards to $\mathrm{HZ}$ incidence and chickenpox exposure and its clinical relevance was limited by the fact that it did not take disease severity or the development of PHN into consideration (Chaves et al 2007c). The most recently conducted epidemiological study of the general population examining HZ incidence took place from 2000-2001, five years after the FDA-approval of Varivax (Insinga et al 2005). Although there was no increase in incidence of $\mathrm{HZ}$ compared with studies from 10-20 years earlier, widespread administration of Varivax had only just begun, in 1997 vaccination coverage among children 19-35 months was only $27 \%$, and the long-term effects of childhood vaccination on $\mathrm{HZ}$ incidence may yet to be seen (Insinga et al 2005; Marin et al 2007).

Although the existing evidence is extremely persuasive to promote routine vaccination for those ages 60 and older, uncertainties do remain. As any clinician knows, the elderly patient often has many existing comorbidities. In the SPS however, only $6.5 \%$ of study subjects were 80 years of age or older, only about $11 \%$ had diabetes mellitus, and most subjects with COPD were excluded because of corticosteroid use. Thus safety and efficacy data in these groups, which make up a large population of most practices, is limited.

Another unanswered question is how long the protective effect of Zoster Vaccine Live will last. The SPS demonstrated a length of protection of at least four years, but it is possible that it is effective for a great deal longer (Oxman et al 2005). The length of vaccine effect could be influenced by multiple factors including the vaccine dose, as well as 
the subject's age and health status. Participants in the SPS received varying dosages of vaccine but the analysis of data did not examine whether those who received higher doses experienced fewer episodes of HZ, or whether they succumbed to more adverse events. An intriguing study was recently performed in the United States, Canada, and Europe. It compared the safety profile of two VZV vaccines, one containing 58,000 PFU of the live-attenuated $\mathrm{Oka} /$ Merck strain (slightly higher than the median number of PFU in the SPS) and the other with 207,000 PFU (Tyring et al 2007). 698 subjects, aged 50-90 were enrolled, and clinically acceptable tolerability was predefined based on experiences with PNEUMOVAX $23^{\circledR}$, another vaccine routinely administered to this age group. Although the rate of injection-site adverse events was greater in the group receiving higher doses, it did not exceed the prespecified criteria for clinically acceptable tolerability. This result is promising on two different fronts; first, as time passes and our experience with Zoster Vaccine Live grows, we may find that the provided immunity to $\mathrm{HZ}$ wanes with time. This study offers evidence that large-scale trials with even higher doses of the vaccine may be employed to attempt to confer longer-lasting protection. Second, this trial included adults aged 50-59, a group which was excluded from the SPS. Although patients aged 60 and older are the most likely to develop HZ, the incidence of HZ first begins to rise after 50 years of age. Since the completion of the SPS, questions have been raised regarding the applicability of the CDC recommendations to those aged 50-59. Although this study show a higher percentage of injection-site reactions in the 50-59 age group compared with the 60 and older age group, no person in either group experienced a serious adverse event related to the vaccine during the study. Further follow-up needs to be undertaken to determine whether vaccination is efficacious and cost effective in adults age 50-59. There is a possibility that a more robust immune response in this age group may lead to higher rates of long-lasting protective immunity following vaccination.

$\mathrm{HZ}$ is seen with greater frequency in immunocompromised people; this group was excluded from the SPS due to safety concerns regarding administration of a live virus. The seriousness of this threat has been confirmed with reported cases of severe Oka strain VZV infection in a heart transplant recipient (Kraft and Shaw 2006), an HIV positive patient (Kramer et al 2001), and a patient with a primary deficiency in natural killer T cells (Levy et al 2003) among others. These cases are clear examples of how the attenuated vaccine virus has the potential to become latent and later reactivate to cause vaccine virus strain (Oka-strain) HZ (Takayama et al 2000). In cases where disease course or treatment allows a physician to predict a future deterioration in immune status, it remains to be seen whether preemptive vaccination will be safe or efficacious in reducing the incidence of $\mathrm{HZ}$. One recent study examined the use of a heat-inactivated VZV vaccine before and after hematopoietic-cell transplantation for Hodgkin's or Non-Hodgkin's lymphoma in 111 patients (Hata et al 2002). In this small trial, the incidence of $\mathrm{HZ}$ was significantly reduced in vaccinated patients and vaccine-related adverse events were limited to injection site reactions (Hata et al 2002). These results suggest that the use of heat-inactivated virus vaccine may be effective and safe in immunocompromised patients and additional trials should be undertaken in other, more varied populations.

Until more time has passed, and regular use of Zoster Vaccine Live has been instituted throughout the country, the uncertainties regarding length of vaccine efficacy, the possible need for second "booster" shots, and the cost-effectiveness of a routine vaccination program cannot be fairly or completely addressed. The results of the SPS are extremely promising and convincing enough to persuade the CDC and the FDA to act upon them. This large, well-designed clinical trial supports the effectiveness of Zoster Vaccine Live in preventing first episodes of $\mathrm{HZ}$ and significantly reducing the burden of illness in adults aged 60 and older. Just as importantly, vaccination decreased the incidence and severity of PHN, one of the most troublesome aspects of HZ. The data from the SPS, along with the vaccine's safety profile, relatively low-cost, and ability to prevent considerable pain and suffering in elderly individuals, lead us to offer our support for the prescription of Zoster Vaccine Live to immunocompetent adults aged 60 and over.

\section{References}

Adour KK. 1994. Otological complications of herpes zoster. Ann Neurol, 35(Suppl):S62-4.

Brisson M, Edmunds WJ, Law B, et al. 2001. Epidemiology of varicella zoster virus infection in Canada and the United Kingdom. Epidemiol Infect, 127:305-14.

Buchbinder SP; Katz MH; Hessol NA, et al. 1992. Herpes zoster and human immunodeficiency virus infection. J Infect Dis, 166:1153-6.

Burke MS. 2007. Herpes Zoster Vaccine; Clinical trial evidence. J Am Osteopath Assoc, 107:S14-S18.

Caranasos GJ, Stewart RB, Cluff LE. 1974. Drug-induced illness leading to hospitalization. JAMA, 228:713-17.

Chaves S. 2007a. Update on safety of Herpes Zoster Vaccine. Presented at the Advisory Committee on Immunization Practices meeting, Atlanta, GA. June 30, 2006 [online]. Accessed October 11, 2007. URL: http://www.cdc.gov/vaccines/recs/acip/downloads/mtg-slides-jun07/ 12-zoster-chavez.pdf. 
Chaves SS, Gargiullo P, Zhang JX, et al. 2007b. Loss of vaccine induced immunity to varicella over time. $N$ Engl J Med, 356:1121-9.

Chaves SS, Santibanez TA, Gargiullo P, et al. 2007c. Chickenpox exposure and herpes zoster disease incidence in older adults in the US Public Health Rep, 122:155-9.

Cohen JI, Brunell PA, Straus SE, et al. 1999. Recent advances in varicellazoster virus infection. Ann Intern Med, 130:922-32.

Davis MM, Patel MS, Gebremariam A. 2004. Decline in varicella-related hospitalizations and expenditures for children and adults after introduction of varicella vaccine in the United States. Pediatrics, 114:786-92.

Dworkin RH, White R, O'Conner AB, et al. 2007. Healthcare costs of acute and chronic pain associated with a diagnosis of herpes zoster. $J$ Am Geriatr Soc, 55:1168-75.

Eaglestein WH, Katz R, Brown JA. 1970. The effects of early corticosteroid therapy on the skin eruption and pain of herpes zoster. JAMA, 211:1681-3.

Esmann V, Geil JP, Kroon S, et al. 1987. Prednisolone does not prevent post-herpetic neuralgia. Lancet, 2:126-9.

Galil K, Choo PW, Donahue JG, et al. 1997. The sequelae of herpes zoster. Arch Intern Med, 157:1209-13.

Galbraith AW. 1983. Prevention of post-herpetic neuralgia by amantadine hydrochloride (Symmetrel). Br J Clin Pract, 37:304-6.

Garweg J, Bohnke M. 1997. Varicella-zoster virus is strongly associated with atypical necrotizing herpetic retinopathies. Clin Infect Dis, 24:603-8.

Gilden DH, Kleinschmidt-DeMasters BK, LaGuardia JJ, et al. 2000 Neurologic complications of the reactivation of varicella-zoster virus. $N$ Engl J Med, 342:635-45.

Glesby MJ, Moore RD, Chaisson RE. 1993. Herpes zoster in patients with advanced human immunodeficiency virus infection treated with zidovudine. Zidovudine Epidemiology Study Group. J Infect Dis, 168:1264-8.

Gnann JW, Whitley RJ. 2002. Herpes Zoster. N Engl J Med, 347:340-6.

Hata A, Asanuma H, Rinki M, et al. 2002. Use of an inactivated varicella vaccine in recipients of hematopoietic-cell transplants. $N$ Engl J Med, 347:26-34.

Häusler M, Schaade L, Kemény S, et al. 2002. Encephalitis related to primary varicella-zoster virus infection in immunocompetent children. J Neurol Sci, 195:111-16.

Hope-Simpson RE. 1965. The nature of herpes zoster: A long-term study and a new hypothesis. Proc R Soc Med, 58:9-20.

Hornberger J, Robertus K. 2006. Cost-effectiveness of a vaccine to prevent herpes zoster and post-herpetic neuralgia in older adults. Ann Intern Med, 145:317-25.

Im M, Kim BJ, Seo YJ, et al. 2007. Complete ophthalmoplegia after herpes zoster. Clin Exp Dermatol, 32:162-4.

Insinga RP, Itzler RF, Pellissier JM, et al. 2005. The Incidence of herpes zoster in a United States administrative database. J Gen Intern Med, 20:748-53.

Katz J, Melzack R. 1999. Measurement of pain. In: Surgical Clinics of North America. Elsevier: Pub, 231-52.

Kawajiri S, Tani M, Noda K, et al. 2007. Segmental zoster paresis of limbs: Report of three cases and review of literature. Neurologist, 13:313-17.

Keczkes K, Basheer AM. 1980. Do corticosteroids prevent post-herpetic neuralgia? Br J Dermatol, 102:551-5.

Kilgore PE, Kruszon-Moran D, Seward JF, et al. 2003. Varicella in Americans from NHANES III: Implications for control through routine immunization. J Med Virol, 70:S111-S118.

Kimberlin DW, Whitley RJ. 2007. Varicella-Zoster vaccine for the prevention of herpes zoster. $N$ Engl J Med, 356:1338-43.

Kost RG, Straus SE. 1996. Post-herpetic neuralgia - pathogenesis, treatment, and prevention. N Engl J Med, 335:32-42.

Kraft JN, Shaw JC. 2006. Varicella infection casued by Oka strain vaccine in a heart transplant recipient. Arch Dermatol, 142:943-5.

Kramer JM, LaRussa P, Tsai WC, et al. 2001. Disseminated vaccine strain varicella as the acquired immunodeficiency syndrome-defining illness in a previously undiagnosed child. Pediatrics, 108:E39.
Kroger AT, Atkinson WL, Marcuse EK, et al. 2006. General recommendations on immunization: recommendations of the Advisory Committee on Immunization Practices (ACIP). MMWR Recomm Rep, 55:1-48.

Legami VD, Gianino MM, Atti MCD, et al. 2007. Epidemiology and costs of herpes zoster: Background data to estimate the impact of vaccination. Vaccine, 25:7598-604.

Levin MJ. 2001. Use of varicella vaccines to prevent herpes zoster in older individuals. Arch Virol Suppl, 17:151-60.

Levin MJ, Smith JG, Kaufhold RM, et al. 2003. Decline in varicellazoster virus (VZV)specific cell-mediated immunity with increasing age and boosting with a high-dose VZV vaccine. J Infect Dis, 188:1336-44.

Levy O, Orange JS, Hibberd P, et al. 2003. Disseminated varicella infection due to the vaccine strain of varicella-zoster virus, in a patient with a novel deficiency in natural killer T cells. $J$ Infect Dis, 188:948-53.

Marin M, Güris D, Chaves SS, et al. 2007. Prevention of varicella, recommendations of the Advisory Committee on Immunization Practices (ACIP). MMWR, 56:1-40.

Merck. 2007. Zoster Vaccine Live: Full prescribing information for healthcare professionals [online]. Accessed June 4, 2007. URL: http://www. zostavax.com.

Messonnier ML, Zhou F. 2006. Review of economic studies of varicella zoster vaccine. Presentation to the ACIP, Atlanta, 25 October.

Nguyen HQ, Jumaan AO, Seward JF. 2005. Decline in mortality due to varicella after implementation of varicella vaccination in the United States. N Engl J Med, 352:450-8.

Opstelten W, Mauritz JW, de Wit NK, et al. 2002. Herpes zoster and postherpetic neuralgia: incidence and risk indicators using a general practice research database. Family Practice, 19:471-5.

Oxman MN, Levin MJ, Johnson GR, et al. 2005. A vaccine to prevent herpes zoster and postherpetic neuralgia in older adults. $N$ Engl J Med, 352:2271-84.

Oxman MN. 2007. Vaccination to prevent herpes zoster and postherpetic neuralgia. Hum Vaccin, 3:64-8.

Pellissier J; The Zostavax Outcomes Research Team. 2006. Evaluation of the cost-effectiveness in the US of a vaccine to prevent herpes zoster and postherpetic neuralgia in older adults. Presented at the advisory committee on immunization practices meeting, Atlanta, GA, June 30, 2006. Record of the proceedings. pp. 60-3 [online]. Accessed 2007. URL: http://www.cdc.gov/vaccines/recs/acip/downloads/ min-jun06.pdf.

Petursson G, Helgason S, Gudmundsson S, et al. 1998. Herpes zoster in children and adolescents. Pediatr Infect Dis $J, 10: 905-8$.

Rice AS, Maton S; Postherpetic Neuralgia Study Group. 2001. Gabapentin in post-herpetic neuralgia: a randomized, double blind, placebo-controlled trial. Pain, 94:215-24.

Rothberg MB, Virapongse A, Smith KJ. 2007. Cost-effectiveness of a vaccine to prevent herpes zoster and postherpetic neuralgia in older adults. Clin Infect Dis, 44:1280-8.

Rowbotham M, Harden N, Stacey B, et al. 1998. Gabapentin for the treatment of postherpetic neuralgia: a randomized, controlled trial. JAMA, 280:1837-42.

Saarto T, Wiffen P. 2007. Antidepressants for neuropathic pain. Cochrane Database Syst Rev, 4:CD005454.

Schmader K. 2007. Herpes zoster and postherpetic neuralgia in older adults. Clin Geriatr Med, 23:615-32.

Schmader KE, Sloane R, Pieper C, et al. 2007b. The impact of acute herpes zoster pain and discomfort on functional status and quality of life in older adults. Clin J Pain, 23:490-6.

Schmader KE, George LK, Hamilton JD. 1995. Racial differences in the occurrence of herpes zoster. J Infect Dis, 171:701-5.

Taha Y; Scott FT; Parker SP, et al. 2006. Reactivation of 2 genetically distinct varicella-zoster viruses in the same individual. Clin Infect Dis, 43:1301-3.

Takayama N, Takayama M, Takita J. 2000. Herpes zoster in healthy children immunized with varicella vaccine. Pediatr Infect Dis $J$, 19:169-70. 
Tassone DM, Boyce E, Guyer J, et al. 2007. Pregabalin: A novel 7 -aminobutyric acid analogue in the treatment of neuropathic pain, partial-onset seizures, and anxiety disorders. Clin Ther, 29:26-48.

Tyring SK, Diaz-Mitoma F, Padget LG, et al. 2007. Safety and tolerability of a high-potency zoster vaccine in adults $>50$ years of age. Vaccine, 25:1877-83.

[USCB] United States Census Bureau Homepage. 2004. Table 2a. Projected population of the U.S. by age and sex: 2000 to 2050 [online]. Accessed 2007. URL: http://www.census.gov/ipc/www/ usinterimproj/.
Vander Straten M, Carrasco D, Lee P, et al. 2001. Reduction of Postherpetic neuralgia in HZ. J Cutan Med Surg, 5:409-16.

Wood MJ, Johnson RW, McKendrick MW, et al. 1994. A randomized trial of Acyclovir for 7 and 21 days with and without prednisolone for treatment of acute herpes zoster. $N$ Engl J Med, 330:896-900.

[WHO] World Health Organization. 2007. Definition of an older or elderly person [online]. Accessed October 15, 2007. URL: http://www.who. int/healthinfo/survey/ageingdefnolder/en/index.html.

Young L. 2006. Post-herpetic neuralgia: A review of advances in treatment and prevention. J Drugs Dermatol, 5:939-42. 